\title{
TOTAL MYOCARDIAL REVASCULARIZATION WITH ARTERIAL CONDUITS: RADIAL ARTERY COMBINED WITH INTERNAL THORACIC ARTERIES
}

Ernesto E. Weinschelbaum, MD Eduardo D. Gabe, MD $^{\mathrm{b}}$

Alejandro Macchia, $\mathrm{MD}^{\mathrm{b}}$

Raffaele Smimmo, $\mathrm{MD}^{\text {a }}$

Luis D. Suárez, MD
Objective: We prospectively tested the feasibility of achieving total arterial revascularization with the use of the radial artery to revascularize the circumflex, diagonal, and right coronary arteries combined with a left internal thoracic artery graft to the left anterior descending artery and, in some cases, a right internal thoracic artery graft to the right coronary artery. Methods: In 164 patients, the radial artery was used as a free $Y$ or $T$ graft from the left internal thoracic artery. Of 568 grafts (3.5 \pm 1 [standard deviation] per patient), $296(1.8 \pm 0.8$ per patient) were constructed with the radial artery as single grafts or as double, triple, or quadruple sequential anastomoses to the circumflex, diagonal, and posterior descending arteries. Diltiazem was administered to prevent spasm. Forty-six patients underwent coronary angiography before discharge from the hospital. Follow-up time was 1 to $19(9.5 \pm 6.1)$ months. Results: Total arterial revascularization was achieved in 137 patients $(83.5 \%)$. Three $(1.8 \%)$ died postoperatively of sepsis, ventricular fibrillation, and heart failure, respectively. Three $(1.8 \%)$ had postoperative myocardial infarction. No hand ischemia occurred. Angiography showed patency of all arterial conduits. Radial artery spasm appeared in $3(6.5 \%)$ of 46 angiograms. Two patients $(\mathbf{1 . 2 \%})$ died during the follow-up period of pneumonia and gastrointestinal tract bleeding, respectively. No other events or reoperations occurred, and 95.1\% of the patients are free of symptoms. Conclusions: The radial artery, as a free $Y$ or $T$ graft from the left internal thoracic artery to the circumflex, diagonal, and right coronary arteries, permits total arterial revascularization with excellent patency rates, minimal morbidity and mortality, and no need for reoperation. Longer follow-up times are necessary to draw definitive conclusions. (J Thorac Cardiovasc Surg 1997;114:911-6)
C arpentier and associates, ${ }^{1}$ in 1973 , were the first to use the radial artery as an alternative conduit for myocardial revascularization. Its use was then abandoned because of the poor results obtained during that early experience. 2 Two decades later, Acar and coworkers ${ }^{3}$ reported excellent long-term results with use of the radial artery in patients

From the Departments of Cardiovascular Surgery, ${ }^{\mathrm{a}}$ Cardiology, and Clinical Investigation, ${ }^{c}$ The Institute of Cardiology and Cardiovascular Surgery, Favaloro Foundation, Buenos Aires, Argentina.

Received for publication Feb. 6, 1997; revisions requested March 11, 1997; revisions received June 16, 1997; accepted for publication July 21, 1997.

Address for reprints: Ernesto Eduardo Weinschelbaum, MD, Department of Cardiovascular Surgery, Favaloro Foundation, Belgrano 1746, 1093 Buenos Aires, Argentina.

Copyright (C) 1997 by Mosby-Year Book, Inc.

$0022-5223 / 97 \$ 5.00+0 \quad \mathbf{1 2} / \mathbf{1} / \mathbf{8 4 9 5 0}$ undergoing coronary bypass grafting. In addition, they showed that some of the conduits in patients operated on 16 to 18 years earlier were still patent. The most relevant reasons for this success are likely to be the use of calcium antagonists to treat radial artery spasm, modification of the harvesting technique, and cautious manipulation during performance of the anastomoses to thus prevent endothelial damage. Since then, other authors have reported the use of the radial artery and have encouraged its use because of the good results obtained. ${ }^{4-6}$

In our institute, we started using the radial artery as an alternative conduit instead of the saphenous vein in May 1995. In the present prospective study, we analyze the results of bypass grafting in patients in whom the radial artery was used to revascularize the circumflex, diagonal, and right coronary artery territories, in combination with one or both internal thoracic arteries (ITAs) for the remaining territo- 


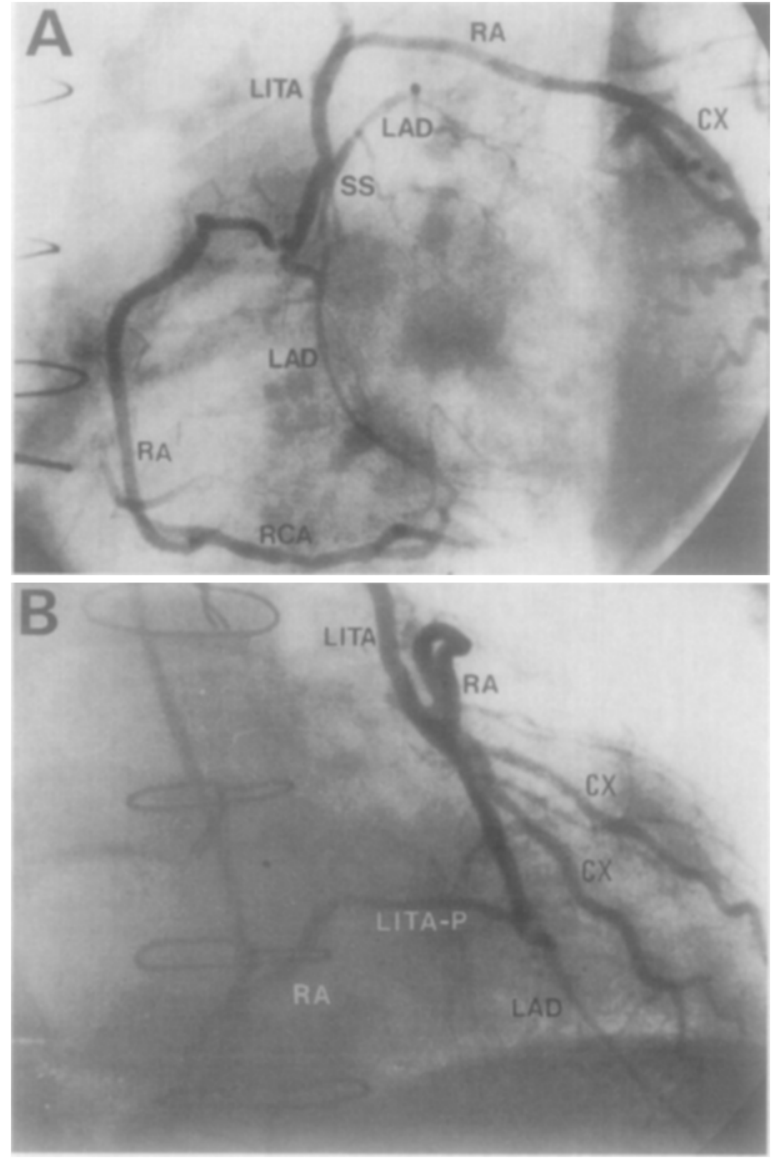

Fig. 1. Revascularization of the entire coronary vascular tree using the left ITA (LITA) as unique inflow vessel, combined with radial artery $(R A)$ grafts. Contrast injected through left ITA only. A, Left anterior oblique view. $R A-C X$, Radial artery graft from left ITA to circumflex branches; $S S$, side-to-side anastomosis of the left ITA with two segments of the $\mathrm{LAD} ; R A-R C A$, radial artery revascularizing the right coronary artery: note that the radial artery is anastomosed end-to-end with a remaining piece of left ITA to reach the trunk of this vessel. B, Right anterior oblique view in the same patient. A piece of the left ITA extending from the radial artery to reach the left ITA is indicated by LITA-P. The radial artery emerges from the left ITA and revascularizes circumflex $(C X)$ branches.

ries, with the radial artery emerging as a $\mathrm{Y}$ or $\mathrm{T}$ anastomosis from the left ITA. In addition, we assessed the feasibility of achieving total arterial revascularization with use of these conduits.

\section{Patients and methods}

Between May 1995 and December 1996, a series of 164 consecutive patients underwent radial artery grafting per- formed by the same surgeon in the Institute of Cardiology and Cardiovascular Surgery of the Favaloro Foundation in Buenos Aires, with a technique in which the radial artery was used to revascularize preferably the territories supplied by the circumflex artery, the right coronary artery, and the diagonal branch of the left anterior descending artery (LAD). In all cases, the radial artery emerged as a $\mathrm{Y}$ or $\mathrm{T}$ graft from the left ITA, which was always connected to the LAD territory (Fig. 1). There were 142 men $(86.6 \%)$ and 22 women $(13.4 \%)$ in the study. Mean age was $62.1 \pm 9.9$ years (range: 37 to 84 years; $95 \%$ confidence interval [CI]: 42.8 to 81.5 ). Thirtyseven patients $(22.6 \%$ ) had an ejection fraction less than $40 \%, 22(13.4 \%)$ had a left main trunk lesion, and 8 $(4.9 \%)$ were undergoing reoperations. Diabetes mellitus was present in 41 patients $(25 \%)$. Of these, $5(12.2 \%)$ received insulin; in $36(87.8 \%)$ the diabetes was controlled with oral medication.

Harvesting technique. The radial artery was harvested only from the nondominant forearm. In all cases, a duplicate evaluation of the irrigation of the hand was made. The first evaluation took place the day before the operation by means of the modified Allen test. ${ }^{7}$ The use of the radial artery was discarded when the test result was positive, and, to maximize safety, it was also ruled out when the result of the test was doubtful. The second evaluation was made in the operating room, with the radial artery exposed but not yet sectioned. While the artery was compressed at its proximal end with two fingers of one hand, the artery was emptied in the distal direction over approximately $20 \mathrm{~cm}$ with two fingers of the other hand. Then, the distal compression was removed, and the circulatory sufficiency of the palmar arch was assessed by observing retrograde arterial repletion. In all cases in which this retrograde repletion was abnormal or considered inadequate, use of the radial artery was discarded.

The radial artery was dissected through a skin incision starting $2 \mathrm{~cm}$ distal to the elbow and ending $3 \mathrm{~cm}$ proximal to the wrist. Excess removal of surrounding tissue was avoided. All collaterals were occluded with the use of hemostatic clips. The length thus obtained ranged from 18 to $20 \mathrm{~cm}$.

Postoperative treatment. To prevent spasm, diltiazem (1 $\mu \mathrm{g} / \mathrm{kg}$ per minute) was infused intraoperatively and during the first 24 hours after operation in all patients and then given orally at a dosage of $240 \mathrm{mg}$ /day for 6 months. Radial artery spasm was considered to exist when a transitory ST segment depression of more than $1.5 \mathrm{~mm}$ that could be reversed by nitroglycerin infusion appeared in the electrocardiographic leads corresponding to the territory revascularized with the radial artery or when a uniform, significant, nitroglycerin-reversible narrowing of the conduit outside the site of anastomosis was evidenced during the angiographic study.

Follow-up. Mean follow-up time was $9.5 \pm 6.1$ months (range 1 to 19 months). In the first 46 patients, a coronary angiogram was performed just before hospital discharge to assess the patency and angiographic characteristics of the radial and ITA grafts. These angiograms consisted exclusively of a single injection of contrast media through the left ITA and, when indicated, through the right ITA. 
Statistics. Values are presented as mean plus or minus the standard deviation. The $95 \%$ CI was calculated. Functional class data were compared with an unpaired $t$ test. A $p$ value $<0.05$ was considered to indicate statistically significant differences.

\section{Results}

Of the original total number of patients in whom the present technique was intended to be used, 26 $(13.6 \%)$ had to be excluded, either because of a positive or doubtful response to the Allen test (23 patients, $12.1 \%$ ) or because of the intraoperative observation of insufficient retrograde circulation through the palmar arch ( 3 patients, $1.5 \%$ ). Results in 164 patients are thus reported.

Number and distribution of coronary anastomoses. A total of 568 grafts were placed, with a mean of $3.5 \pm 1$ per patient (range: 1 to 6 ; $95 \% \mathrm{CI}: 3.3$ to 3.6). Of these, 296 were done with the radial artery (1.8 \pm 0.7 per patient; $95 \%$ CI: 1.7 to 1.9 ), 181 with the left ITA $(1.1 \pm 0.5$ per patient; $95 \%$ CI: 1 to 1.2), 58 with the right ITA $(0.4 \pm 0.5$ per patient; $95 \%$ CI: 0.3 to 0.4$), 32$ with saphenous vein $(0.2 \pm$ 0.5 per patient; $95 \% \mathrm{CI}: 0.1$ to 0.3 ), and the remaining 1 with the gastroepiploic artery. In 113 patients $(68.9 \%)$ only one ITA was used. This was the left ITA in $107(94.7 \%)$ and the right ITA in the remaining 6 patients $(5.3 \%)$. In 49 patients $(29.9 \%)$, both ITAs were used. In 2 patients, neither ITA was used: these were the only 2 cases in which the radial artery grafts emerged from the aorta (one was connected to the LAD and the other to the circumflex artery). The radial artery was used as a single graft in 65 patients (39.6\%) and as a sequential graft in $99(60.4 \%)$. Among the latter, 2 anastomoses were done in 74 patients $(74.7 \%), 3$ in $22(22.2 \%)$ and 4 in 3 (3\%) (Figs. 1, 2, and 3). The sequential anastomoses were transverse, diamond-shaped anastomoses made with running 8-0 Prolene suture. We used this technique because it permits performance of a larger number of anastomoses for any given length of the conduit. When used sequentially, most of the radial artery grafts were connected to the circumflex territory, followed by the diagonal and posterior descending territories (Table I). The in situ left ITA was used to revascularize mainly the LAD territory, either as a single graft in 124 patients $(75.6 \%)$ or sequentially (to the diagonal or to another portion of the LAD) in 26 patients $(15.9 \%)$. The right ITA was generally used to revascularize the right coronary artery bed, as an in situ single graft. Complete revascularization on the basis of
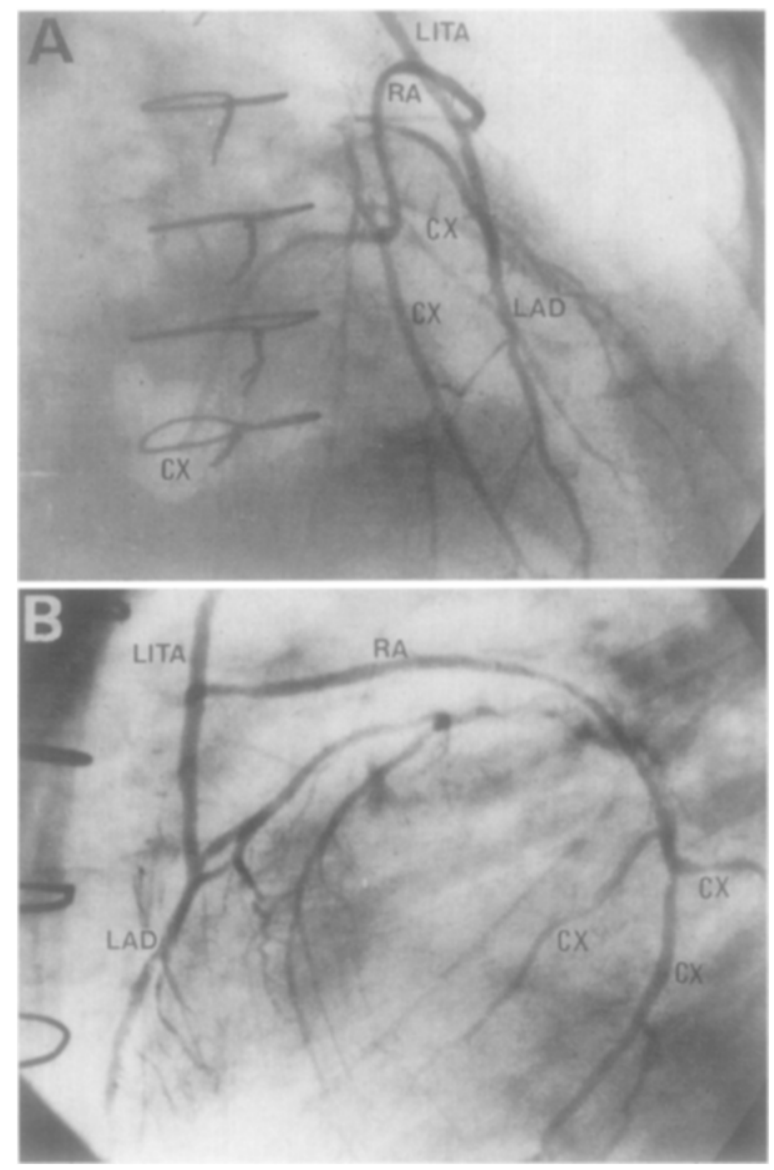

Fig. 2. Total arterial revascularization with the left anterior ITA (LITA) and a triple sequential radial artery graft. Contrast is injected through the left ITA only. A, Right anterior oblique view of the left ITA graft to the LAD and radial artery $(R A)$ grafts to three circumflex $(C X)$ branches. B, Left anterior oblique view obtained in the same patient at the same time.

only arterial conduits was achieved in 137 patients $(83.5 \%)$.

Fifteen patients underwent an associated procedure: mitral valve replacement in 5 , mitral valve repair in 5, carotid endarterectomy in 2, left ventricular aneurysmectomy in 1 , aortic valve replacement in 1 , and aortic valve decalcification in 1 .

Follow-up. In the 46 patients in whom angiograms through the left and right ITAs were done before discharge, all 222 anastomoses and 172 grafts were patent and only 1 graft $(0.6 \%)$ showed a less than $50 \%$ narrowing of the lumen. In 3 patients $(6.5 \%)$, a steal phenomenon of the radial artery to the distal third of the ITA, with no clinical or functional relevance, was observed. Radial artery 


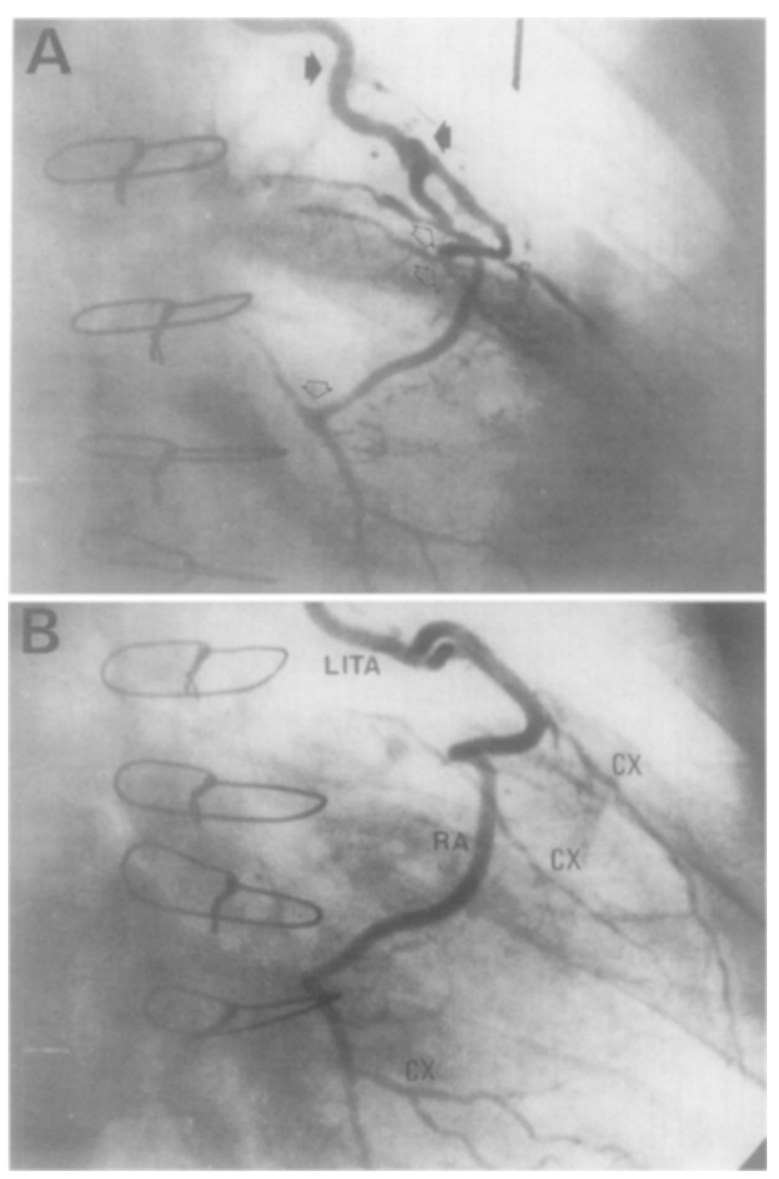

Fig. 3. Total arterial revascularization with the left ITA (LITA) and a double sequential radial artery (RA) graft. Contrast is injected through the LITA only. A, Frontal view. The closed arrow pointing right indicates the left ITA. The closed arrow pointing left shows the emergence of the radial artery from the LITA. The upper open arrow shows the LITA-LAD anastomosis, and the lower two open arrows show anastomoses of the radial artery with two circumflex $(C X)$ branches. B, Right anterior oblique view obtained in the same patient at the same time.

spasm occurred in 3 patients ( $6.5 \%$ of the patients who underwent angiographic study). Because none of the remaining patients showed electrocardiographic criteria for spasm, the calculated overall incidence of radial artery spasm was $0.8 \%$.

Postoperative complications are listed in Table II. Other than transitory dysesthesia of the hand and forearm hematoma (see Table II), no complications associated with the harvesting procedure (including infection, necrosis, ischemic pain, and motor dysfunction) were observed.

Three patients $(1.8 \%)$ died during the early postoperative period: one of septicemia, one of irrevers- ible heart failure, and one of ventricular fibrillation. During the follow-up period, $2(1.2 \%)$ of 161 patients died, one of pneumonia in the second month of follow-up and one of massive gastrointestinal tract bleeding (perforated duodenal ulcer) in the sixth month of follow-up. Of the remaining 159 patients, $5(3.8 \%)$ are in New York Heart Association functional class I or II and $1(0.6 \%)$ is in functional class III or IV ( $p=0.0001$ with respect to preoperative functional class III or IV). The remaining 156 patients ( $95.1 \%$ of the total population) are free of symptoms and the follow-up remains uneventful. No reoperations or coronary angioplasty procedures were needed. It should be noted that diltiazem administration had to be discontinued in 32 patients (20\%) because of undesirable side effects (bradycardia, hypotension, heart failure).

\section{Discussion}

The potential advantages of arterial conduits compared with venous grafts in coronary operations have resulted in their increasing use with the aim of achieving complete myocardial revascularization with them. The biologic characteristics of the vascular wall account for the better patency observed in arterial conduits compared with the patency of the saphenous vein. With regard to early patency, arterial conduits, unlike the saphenous vein, do not develop premature intimal hyperplasia, unless inappropriate surgical manipulation has occurred. ${ }^{8,9}$ Preventing surgical damage is therefore mandatory.

It has been shown that the ITA graft to the LAD has improved long-term survival not only because of a decreased incidence of acute myocardial infarction but also because of a lesser need for reoperations as compared with results after use of the saphenous vein. $^{10,11}$ Because of the long-term advantages of the in situ ITA graft, its use should be almost exclusively directed to the most important myocardial territory, which is generally supplied by the LAD. The other arterial conduits should therefore be used to revascularize the right coronary, diagonal, and circumflex artery territories.

Some authors have shown that the use of double ITA anastomoses is an alternative that allows adequate revascularization with excellent long-term results. ${ }^{12}$ This is another reason for the renewed interest in the radial artery, among other conduits, to achieve complete revascularization with only arterial vessels. Additionally, the similarity of crosssectional areas between these conduits and that of the coronary arteries determines a functional advan- 
Table I. Sequential radial artery grafts $(n=99)$

\begin{tabular}{clrc}
\hline Type of sequence & Distribution & $n$ & Percent \\
\hline Double & CX-CX & 33 & \\
& DG-CX & 20 & \\
& CX-DG & 13 & \\
& PD-CX & 3 & \\
CX-PD & 1 & \\
& DG-PD & 1 & \\
RCA-PD & 1 & \\
& DG-RCA & 1 & \\
RCA-MO & 1 & \\
Triple & Total & 74 & 74.7 \\
& CX-CX-DG & 12 & \\
& CX-CX-CX & 6 & \\
& CX-CX-RCA & 1 & \\
& CX-CX-PD & 1 & \\
& DG-CX-CX & 1 & \\
& PD-CX-DG & 1 & \multirow{6}{*}{ Total } \\
& CX-CX-CX-DG & 22 & 22.2 \\
& CX-CX-DG-PD & 1 & \\
& Total & 3 & 3 \\
\hline
\end{tabular}

$C X$, Circumflex; $D G$, diagonal; $P D$, posterior descending; $R C A$, right coronary artery; $M O$, marginal obtuse.

tage, especially in light of the gross disparity between the lumen of the coronary arteries and that of the saphenous vein. We should not disregard another important reason for encouraging total arterial revascularization: the lower limb complications derived from the use of saphenous veins are avoided. This, in turn, may result in earlier ambulation, a shorter hospital stay, and a faster return to daily activities.

The present report shows the feasibility of achieving multiple revascularization by combining the use of the radial artery with use of one or both ITAs. This is not only because of the length of the conduit (18 to $20 \mathrm{~cm}$ ), but also (and most important) because the $\mathrm{Y}$ or $\mathrm{T}$ anastomosis technique from the ITA permits the construction of two to four sequential anastomoses in the circumflex, right coronary, and diagonal artery territories. Additionally, the $\mathrm{Y}$ or $\mathrm{T}$ anastomosis technique allows placement of the radial artery in a hemodynamic condition similar to its native situation, that is, in that of a fourth-order artery, as has been pointed out by Calafiore and associates. $^{5}$ In contrast, when the radial artery is anastomosed directly to the aorta, it is exposed not only to a higher pressure but also to higher shear stress, which, given its histologic characteristics, favors the early development of intimal alterations leading to obstruction. The accelerated intimal hyperplasia described by Curtis and coworkers ${ }^{13}$ in a retrospective analysis may be attributed mainly to
Table II. Postoperative complications

\begin{tabular}{lrc}
\hline \multicolumn{1}{c}{ Complication } & $n$ & Percent \\
\hline Acute myocardial infarction & 3 & 1.8 \\
Atrial fibrillation & 32 & 19.5 \\
Heart failure & 27 & 16.5 \\
Intraortic balloon counterpulsation & 4 & 2.4 \\
Pneumonia & 4 & 2.4 \\
Mediastinitis & 3 & 1.8 \\
Transitory dysesthesia of the hand & 26 & 15.9 \\
Hematoma of the harvesting site & 6 & 3.7 \\
\hline
\end{tabular}

focal intimal damage resulting from excess dilation during preparation of the conduit, as well as from excess removal of the surrounding tissue (skeletonization). This would provoke a deprivation of vasa vasorum and impaired lymphatic drainage, leading to ischemia of the conduit. ${ }^{13}$

Given its prominent muscular layer, the radial artery is particularly sensitive to mechanical stimuli and reacts with spasm. ${ }^{14}$ However, in the present study, arterial spasm did not represent a serious inconvenience. Except for in 3 patients, there were no angiographic, electrocardiographic, or clinical signs of artery spasm. On the other hand, none of the 26 patients in whom diltiazem administration had to be discontinued because of its adverse side effects had symptoms (or events) compatible with spasm.

An additional advantage of the radial artery with respect to other arterial conduits is its easy access and availability: in only $15 \%$ of the patients did this approach have to be discarded because of a positive Allen test result or because of intraoperative observation of inadequate supplementary flow through the palmar arch.

The probability of inducing significantly low myocardial blood flow may be a potential disadvantage of the use of arterial conduits, especially in patients with impaired left ventricular function or preexisting heart failure. This loss of flow would be the consequence of vasospasm and of the technical difficulties associated with the construction of multiple ITAradial or radial-coronary anastomoses. ${ }^{9}$ This was not the case in the present series, in which the incidences of perioperative acute myocardial infarction and of intraaortic balloon counterpulsation were only $1.8 \%$ and $2.4 \%$, respectively.

It should be noted that the preoperative and intraoperative tests to assess adequate supplementary irrigation through the palmar arch were safe and reliable, inasmuch as none of the 164 patients had at any time during follow-up any symptom or 
sign associated with ischemia of the hand or forearm from which the radial artery was harvested.

Limitations. An important limitation of our study is the shortness of the follow-up period, which prevents any conclusion about long-term patency of these grafts. The most recent data in this regard are those of Acar and colleagues, ${ }^{15}$ who showed in 50 cases an $84.5 \%$ patency rate at 5.6 years, compared with an $89.8 \%$ rate for the ITA. With regard to saphenous vein grafts, Campeau and colleagues ${ }^{16}$ have reported patency rates of $76 \%$ at 1 year, $67 \%$ at 5 to 7 years, $47 \%$ at 10 to 12 years, and $35.7 \%$ at 17 to 23 years. It must be emphasized that although the results of Acar and colleagues ${ }^{15}$ are promising, more long-term studies are needed to firmly encourage the use of this technique.

\section{Conclusions}

The use of the radial artery in combination with one or both ITAs permits total arterial myocardial revascularization in a great majority of patients, with minimal morbidity and mortality in the short term. Ischemic complications of the arm and hand are not to be expected if careful preoperative and intraoperative evaluation of sufficient retrograde circulation through the palmar arch is made. Although the rates of patency at 9 months were excellent, longer periods of follow-up and the results of other authors are mandatory to indicate routine use of the radial artery combined with the ITAs in myocardial revascularization.

We thank Drs. Alberto Crottogini, Jorge Negroni, and Elena Lascano from the Basic Sciences Research Institute (Favaloro Foundation) for helping in the preparation of the manuscript.

\section{REFERENCES}

1. Carpentier A, Guermonprez JL, Deloche A, Frechette C, DuBost $C$. The aorta-to-coronary radial artery bypass graft: a technique avoiding pathological changes in grafts. Ann Thorac Surg 1973;16:111-21.

2. Carpentier A. Discussion of: Geha AS, Krone RJ, McCormick JR, Baue AE. Selection of coronary bypass: anatomic, physiological, and angiographic considerations of vein and mammary artery grafts. J Thorac Cardiovasc Surg 1975;70: 429-30.

3. Acar C, Jebara VA, Portoghese M, et al. Revival of the radial artery for coronary bypass grafting. Ann Thorac Surg 1992; 54:652-60.

4. Dietl C, Benoit C. Radial artery graft for coronary revascularization: technical considerations. Ann Thorac Surg 1995; 60:102-10.

5. Calafiore A, Teodori G, Di-Giammarco G, et al. Coronary revascularization with the radial artery: new interest for an old conduit. J Card Surg 1995;10:140-6.

6. Brodman RF, Frame R, Camacho M, Hu E, Chen A, Hollinger I. Routine use of unilateral and bilateral radial arteries for coronary artery bypass graft surgery. $\mathrm{J}$ Am Coll Cardiol 1996;28:959-63.

7. Ejrup B, Fischer B, Wright IS. Clinical evaluation of blood flow to the hand. Circulation 1966;33:778-80.

8. van Son JM, Smedts F, Vincent JG, van Lier HJ, Kubat K. Comparative anatomic studies of various arterial conduits for myocardial revascularization. J Thorac Cardiovasc Surg 1990; 99:703-7.

9. Barner HB. Defining the role of the radial artery. Semin Thorac Cardiovasc Surg 1996;8:3-9.

10. Loop FD, Lytle BW, Cosgrove DM, et al. Influence of the internal-mammary-artery graft on 10-year survival and other cardiac events. N Engl J Med 1986;314:1-6.

11. Cameron A, Davis KB, Green G, Schaff HV. Coronary bypass surgery with internal thoracic artery grafts: effects on survival over 15-year period. N Engl J Med 1996;334: 216-9.

12. Galbut DL, Traad EA, Dorman MJ, DeWitt PL, Larsen PB, Kurlansky PA. Seventeen-year experience with bilateral internal mammary artery grafts. Ann Thorac Surg 1990;49:195201.

13. Curtis JJ, Stoney WS, Alford WC Jr, Burrus GR, Thomas CS. Intimal hyperplasia: a cause of radial artery aortocoronary bypass graft failure. Ann Thorac Surg 1975;20:628-35.

14. Spence PA, Montgomery WD, Santamore WP. High flow demand on small arterial coronary bypass conduits promotes graft spasm. J Thorac Cardiovase Surg 1995;110:952-62.

15. Acar C, Ramshey A, Pagny JY, et al. Five-year results of coronary bypass grafting using the radial artery. Proceedings of the Seventy-seventh Annual Meeting of The American Association for Thoracic Surgery. Washington DC: 1997. p. 100-1.

16. Campeau L, Lespérance J, Poitras AM, Leclerc D, Castonguay $\mathrm{Y}$. Saphenous vein coronary artery bypass graft patency up to 22 years after grafting [Abstract]. Circulation 1993; 88(pt II):1388. 